\title{
Role of fine mode aerosols in modulating cloud properties over industrial locations in north India
}

\author{
B. Abish and K. Mohanakumar \\ Department of Atmospheric Sciences, Cochin University of Science and Technology, Cochin - 682016, India \\ Received: 20 March 2011 - Revised: 24 July 2011 - Accepted: 11 September 2011 - Published: 16 September 2011
}

\begin{abstract}
The influence of aerosols on cloud properties over North India which includes the Indo-Gangetic Plain has been investigated for the years 2000 to 2010. During the years 2004, 2009 and 2010 there has been an abrupt increase in fine mode aerosol optical depth (AOD) inducing a sharp decline in cloud effective radius (CER) in the month of January. The following monsoon during these years was a failure in the region considered for the study. In the year 2010, a highest AOD value of 0.35 was recorded in the month of January. In accordance with the aerosol indirect effect, this large increase in AOD resulted in a significant reduction in CER. The monsoon season in that year was deficient in the study region even though the rest of the country received above normal rainfall. For the years when CER diminished below 12 microns in the month of May, a delay in the advancement of monsoon towards North India is noted even after a normal or early onset in southern peninsula. Meanwhile, a rapid progression took place when it was 12 microns or above. During non-monsoon months an inverse relationship existed between cloud effective radius and liquid water path and a strong positive association occurred in the monsoon months. Present analysis suggests that the excessive aerosol loading and the associated aerosol indirect effects in the months prior to the monsoon season has an effect on the propagation and onset of the south west monsoon over the region.
\end{abstract}

Keywords. Atmospheric composition and structure (Aerosols and particles)

\section{Introduction}

It has been well established through modelling and observational studies that the properties of clouds located in the vicinity of high aerosol concentrations are altered significantly (Ackerman et al., 2000; Penner et al., 2004; Koren

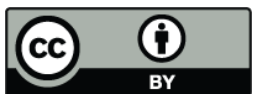

Correspondence to: $\mathrm{B}$. Abish (abishb@gmail.com) et al., 2005; Rosenfeld et al., 2006). The first indirect effect or "Twomey effect" says that in a polluted environment, the intensification of aerosols will lead to an increase in available cloud condensation nuclei $(\mathrm{CCN})$ for cloud formation (Twomey, 1977). Therefore, the presence of large amount of $\mathrm{CCN}$ in the atmosphere results in smaller cloud droplets. A decrease in droplet size has the additional effect of delaying the onset of collision and coalescence in warm clouds, reducing precipitation efficiency. As a result the cloud liquid water path increases along with the lifetime of the cloud (Albrecht, 1989) which is termed as second indirect effect.

Martins et al. (2009) has suggested that biomass burning aerosols delay the onset of precipitation through slower droplet growth. Rosenfeld (1999) and Rosenfeld and Woodley (2000) using aircraft data together with satellite data demonstrated that in a polluted environment there is indeed a suppression of rainfall due to the smaller size of cloud droplet. This was later confirmed by a modelling study with a cloud resolving model by Khain et al. (2001). In short, in a polluted environment both the first and second aerosol indirect effects lead to a reduction in precipitation (Ramanathan et al., 2001) thereby causing a serious impact on regional climate (Liao and Seinfeld, 1998; Chung and Ramanathan, 2004).

The aerosol optical depth is another parameter that has a significant contribution to the radiative forcing whose mean value is highly dependent on the meteorological conditions and altitude at a given locality (Bhawar and Devara, 2010). The potential effects of aerosol forcing on clouds and precipitation has been expounded upon in recent years (Menon et al., 2002; Miller et al., 2004; Lau and Kim, 2006; Gautam et al., 2009). An important factor mentioned in these works is the aerosol induced thermodynamic effect resulting from solar absorption by aerosols. This absorption of solar radiation at the top of the atmosphere causes local heating of the atmosphere and surface cooling. This could affect the atmospheric stability creating a temperature gradient between the area underneath the aerosol layer and surrounding region (Wang et al., 2009).

Published by Copernicus Publications on behalf of the European Geosciences Union. 


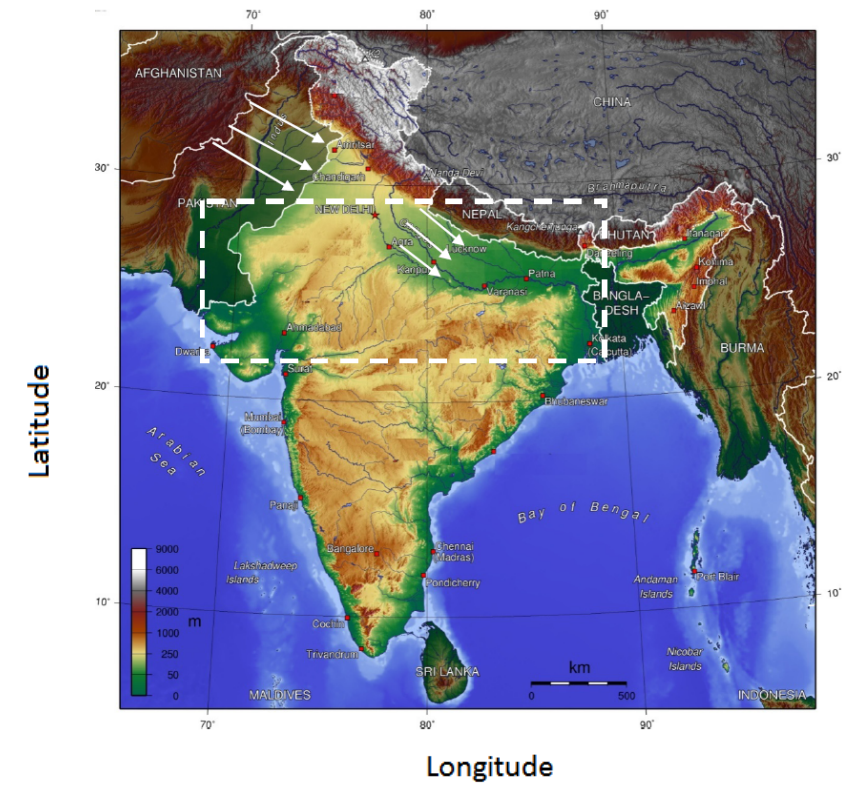

Fig. 1. Map of India with grid chosen for the study. Major industrial and urban locations are also shown.

By means of atmospheric model, Lau et al. (2006) showed that the accumulation of aerosols in the southern slopes of the Himalayas alters the vertical and meridional heating profiles during pre-monsoon months. Using coupled oceanatmospheric model, Ramanathan and Ramana (2005) has reported that aerosols in the region lead to a weakening of monsoon circulation and a reduction of rainfall. Bollasina et al. (2008) using statistical analysis of observational data found a higher aerosol loading over the Indo-Gangetic Plain (IGP) during the month of May resulted in a lower precipitation over most parts of India. Since, monsoon circulation is governed by the strength of the temperature gradient; any modification of the thermal regime can affect the progress of the Indian summer monsoon. Over the Indian region, only a limited number of studies have been done on the aerosol indirect effects. Using MODerate resolution Imaging Spectroradiometer (MODIS) data these studies both qualitatively and quantitatively suggest that there exists a significant positive aerosol indirect effect over IGP (Tripathi et al., 2007) and is one of the factors that modulate the Indian summer monsoon (Patra et al., 2005; Ravi Kiran et al., 2009; Panicker et al., 2010). However, it is still uncertain how much the accumulation of aerosols in the non-monsoon months affects the onset and progress of succeeding monsoon season.

The present analysis is done for 11 years from 2000 to 2010 over the North Indian region $\left(69^{\circ} \mathrm{E}-89^{\circ} \mathrm{E} ; 21^{\circ} \mathrm{N}-\right.$ $29^{\circ} \mathrm{N}$ ) that includes IGP as shown in Fig. 1. The chosen grid comprises of major industrial cities in India (New Delhi, Kanpur, Allahabad, Jamshedpur and Kolkata). The IGP with its unique valley type topography and rapid increase in population and urbanization has resulted in a sustained increase in aerosol burden during the last decade (Dey et al., 2004; Nair et al., 2007). The region is bounded by the Himalayas in the north, Thar Desert in the west, the Vindhyan mountain range in the south and Brahmaputra river basin in the east. During the non-monsoon months, October to May, the weather in the location is dry with very little rainfall. Surface winds are weak during most of the time in this dry season. These conditions are ideal for the congregation of aerosols and the favourable atmospheric conditions increase the life time of ambient aerosols, resulting in the excessive piling up of aerosols over the region.

The IGP and the surrounding regions are a major source of fine mode aerosols. The emissions from vehicles and industries dominate throughout the year. These sources inject copious amount of aerosols due to the combustion of fossil fuels such as coal, petrol and diesel (Ram and Sarin, 2010). The hygroscopic particles such as sulphates which are emitted from industries are mostly in fine mode and act as good cloud condensation nuclei (Tare et al., 2006). The open burning of crop wastes and forests contribute to the aerosol concentration during the dry months over this region (Habib et al., 2006). During this time dust aerosols also gets transported to the region by means of upper level westerlies (Léon and Legrand, 2003). As the season progresses these dust aerosols and the aerosols due to biomass and fossil fuel burning gets accumulated in the region.

Meteorologically, IGP is a sensitive region because of the location of monsoon trough and also the descending limb of the Hadley Circulation during the summer monsoon season. The position of the Inter Tropical Convergence Zone (ITCZ) is necessary for the progress and the intensity of monsoon circulation. During the northern hemispheric summer season, the apparent position of ITCZ passes through this study region. If any imbalance in the vertical thermal structure occurs due to aerosol forcing, then it will translate into a modification in thermal gradient. The fine mode aerosol particles that reside inside a cloud particle as $\mathrm{CCN}$ can alter the vertical thermal stability by modifying the cloud properties (Wang et al., 2009). The possible impacts of aerosols on the hydrological cycle are very complex. It is interesting to know if there is any aerosol induced effects on monsoon progress and its onset, which is still a least explored facet in atmospheric science.

\section{Data description}

Monthly mean MODIS data onboard Terra and Aqua satellites are used to determine the cloud and aerosol properties over the chosen location with equatorial crossing time 10:30 $\mathrm{h}$ and 13:30 $\mathrm{h}$ local solar time, respectively (Levy et al., 2007). The dataset after March 2010 is taken from Aqua satellite. The C005 Level 3 (spatial resolution $1^{\circ} \times$ $1^{\circ}$ ) MODIS products are obtained from the website (http: //giovanni.gsfc.nasa.gov/). 
Since MODIS cannot directly provide aerosol speciation, fine mode fraction (FMF), which is the ratio of fine mode aerosol optical depth to the total aerosol optical depth, is often used a proxy for delineating anthropogenic fine mode aerosols at $550 \mathrm{~nm}$ from coarse mode aerosols (Bellouin et al., 2008; Jones and Christopher, 2007; Yu et al., 2009). Anthropogenic aerosols such as sulphates and carbonates (black carbon and organic carbon) are considered as fine mode aerosols and they produce high FMF values, whereas natural aerosols which consists of mechanically produced dust and sea salt aerosols are coarse mode in nature resulting in lower FMF values (Kaufman et al., 2005). In this study, fine mode aerosol optical depth at $550 \mathrm{~nm}$ is used to signify the presence of anthropogenically produced aerosols.

The cloud properties analysed in the present study are liquid water path (LWP) and cloud effective radius (CER) in water clouds. The LWP is defined as the column amount of liquid water in the cloud. It has a significant role in the transport of latent heat in the earth-atmosphere system. The CER is an area-weighted mean radius of the cloud droplets and is determined as;

$r_{e}=\frac{\int_{0}^{\infty} r^{3} n(r) d r}{\int_{0}^{\infty} r^{2} n(r) d r}$

where, $r=$ particle radius; $n(r)=$ particle size distribution (number of particles per $\mathrm{cm}^{2}$ with radius in the range $r$ and $r+d r$ microns). The MODIS algorithm uses near infrared to mid-infrared measurements to retrieve CER that are then converted to LWP.

The accuracy of satellite estimates of AOD was first suggested based on theoretical analyses (Kaufman et al., 1997). Over the land, the MODIS-derived AOD are validated against the in situ AOD observed at AERONET stations, which shows that AOD retrievals in the visible wavelengths are generally within the pre-launch uncertainty (Jethva et al., 2007; Remer et al., 2008). An inter-comparison of MODIS derived AOD with AERONET observations over India are found to be in reasonably good agreement with the ground-based sun photometer observations of AOD over the Gangetic plain (O'Neill et al., 2003; Jethva et al., 2005; Aloysius et al., 2008). Uncertainty analysis reveal that for thick clouds the error is CER is less than 0.1 microns, but for thin clouds the error in CER is around 0.3 microns (Tripathi et al., 2007). We recognize the errors involved in the retrieval of aerosol and cloud products from MODIS which is a limitation of this study.

\section{Results and discussion}

\subsection{First indirect effect}

Figure 2 illustrates the monthly mean time series analysis between AOD of fine mode aerosols and cloud effective radius (CER). In order to bring out the AOD and CER vari-
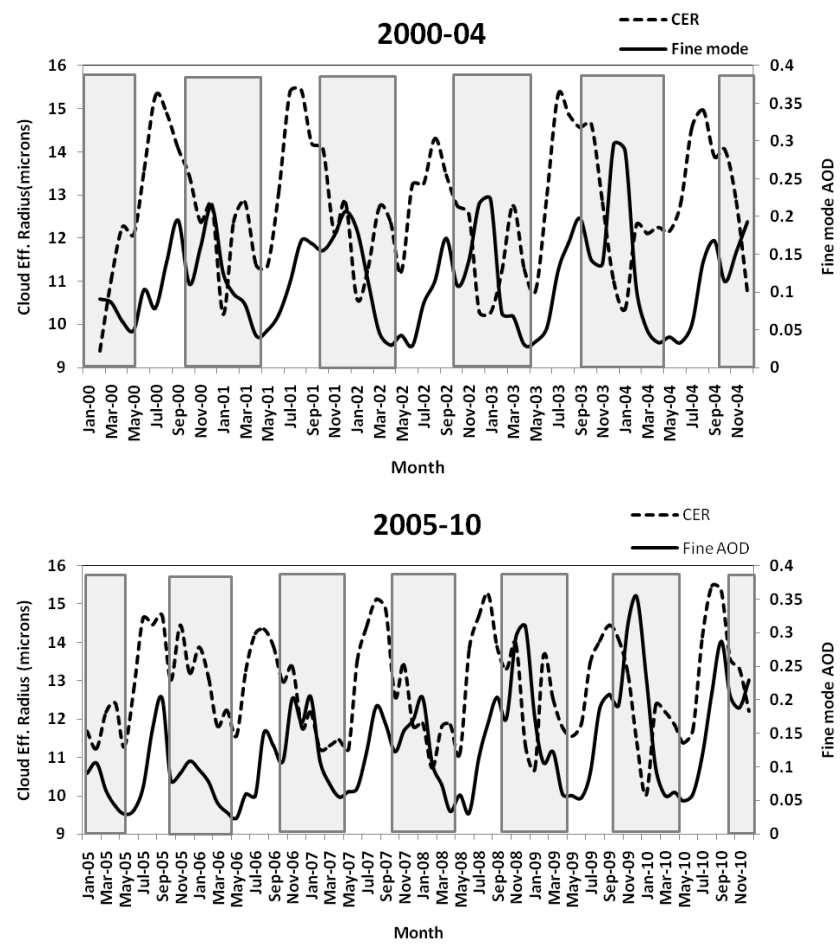

Fig. 2. Monthly mean time series between fine mode AOD and CER. The rectangular boxes indicate the dry months when fine mode AOD and CER shows a negative relation.

ability precisely, the eleven year data is splitted into two panels as shown in the figure. The top panel gives the time series between AOD and CER for the years 2000 to 2004 and the bottom panel that for the years between 2005 and 2010 . The rectangular boxes in both the panels indicate the nonmonsoon months (October to May).

From Fig. 2, it can be seen that AOD undergoes strong seasonality over the region. The fine mode AOD dominates during non-monsoon months in almost all the years except 2005 and 2007. Our analysis reveals that after the year 2002 there is pronounced loading of fine mode aerosols. The figure also shows that whenever there is a large concentration of fine mode aerosols in the non-monsoon months, as evident from the high AOD values, there is a substantial reduction in CER. It is clearly shown in Fig. 2 that when aerosol loading peaks in the month of January there is a subsequent decrease in CER. This relationship is not valid during the monsoon season probably due to the predominance of coarse mode aerosols. To verify the degree of this inverse relationship, a quantitative analysis is done between CER and AOD. A scatter plot is drawn between CER and AOD for the nonmonsoon months and is given in Fig. 3.

It is evident from Fig. 3 is that CER and AOD are highly anti-correlated during the non-monsoon months with a correlation coefficient of -0.62 . This justifies our reasoning that there is in fact a decrease in CER due to an increase in AOD. 


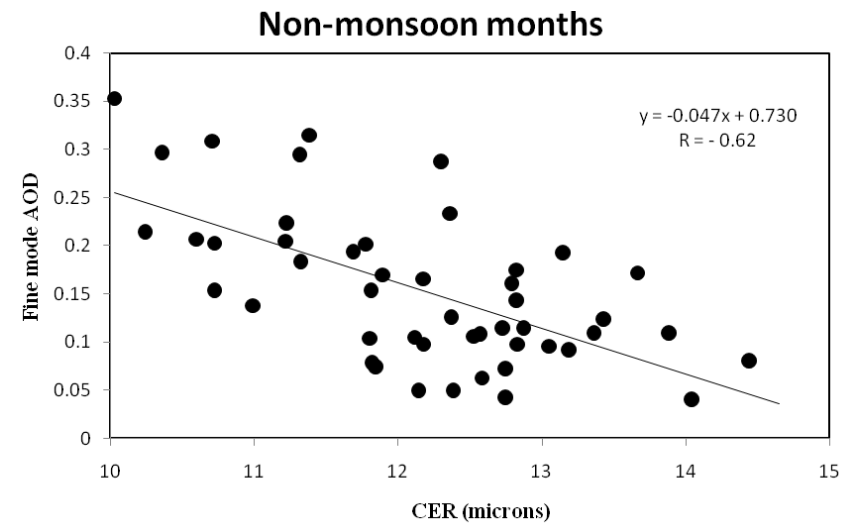

Fig. 3. Scatter plot between fine mode AOD and CER indicating a negative correlation in non-monsoon months.

A notable feature is that for the years, 2004 and 2009, a high AOD of 0.3 occurred in the month of January. Consequently, a decrease of CER below 11 microns is also noticed in the same month. These observations are in concurrence with the first indirect effect in which excessive amount of fine mode aerosols results in the reduction of CER.

In all these years of higher aerosol loading, the following monsoon was a failure in the region considered for the study. The drought conditions that prevailed in 2009 enabled the atmospheric aerosol loading in large quantities. The peak AOD value of 0.35 observed in January 2010, which is the highest in the decade, indicates the large concentration of fine mode aerosols in that year. A reduction of CER to 10 microns, which is also the least value in the decade, is seen in the same month.

According to monsoon report issued by the Indian Meteorological Department (http://www.imd.gov.in/section/nhac/ dynamic/monsoon_report_2010.pdf), the monsoon that followed had a deficit of $24 \%$ in June rainfall for the year 2010 . A reduction in rainfall persisted throughout the monsoon season (June-September) while rest of the country received more than normal rainfall. Even though it is not certain about the exact cause for this reduction in rainfall, it can be postulated that the aerosol forcing and the indirect effect could be a possible reason. Further detailed analysis is required to understand the actual mechanism that drives the monsoon circulation over this region.

The years (2004, 2009 and 2010) also apprehend significance due to El-Niño conditions that prevailed during those occasions. Dry season associated with ElNiño is favourable for the production of aerosols and the absence of rainfall increases its life time over the region. This explains the large AOD seen during the non-monsoon period. Moreover, as indicated by Oceanic Niño Index (http://www.cpc.ncep.noaa.gov/ products/analysis_monitoring/ensostuff/ensoyears.shtml) severe El-Niño conditions occurred in the non-monsoon
Table 1. Monsoon onset dates over Kerala and IGP.

\begin{tabular}{ccc}
\hline Year & Onset (Kerala) & Onset (IGP) \\
\hline 2000 & 1 Jun & 7 Jun \\
2001 & 26 May & 17 Jun \\
2002 & 9 Jun & 20 Jun \\
2003 & 13 Jun & 20 Jun \\
2004 & 3 Jun & 15 Jun \\
2005 & 7 Jun & 23 Jun \\
2006 & 26 May & 24 Jun \\
2007 & 28 May & 18 Jun \\
2008 & 31 May & 12 Jun \\
2009 & 23 May & 28 Jun \\
2010 & 31 May & 4 Jul \\
\hline
\end{tabular}

months of 2010, which justifies the higher aerosol content in that period.

It is well known that monsoon circulation is driven by land sea temperature contrast. Over the Indian region, the entry point of southwest monsoon is through Kerala coast which is situated at the southern part of peninsular India. After normal onset that usually occurs on 1 June, monsoon circulation steadily progresses northwards and normally reaches IGP on 15 June. During the last decade, except for the years 2000 and 2004, even after an early or normal monsoon onset over southern peninsula, the progress and subsequent onset of monsoon got delayed over North India (see Table 1). It may be noted that for all these years CER was well below 12 microns in the month of May. In the years 2006, 2009 and 2010, this delay in onset was so pronounced in North India that even after an early onset in southern peninsula (Kerala), the advancement of monsoon towards North India got delayed by two to three weeks. In 2000 and 2004 the CER was above 12 microns. In 2000, there was a swift advancement of monsoon over North India. During 2004, even though it was a delayed onset over Kerala, the monsoon progressed rapidly towards North India to reach there on actual onset date (Pai and Rajeevan, 2009; http://www.imd.gov.in/ section/nhac/dynamic/Monsoon_frame.htm). If second indirect effect holds then a decrease in CER should decrease the precipitation efficiency leading to an increase in LWP.

\subsection{Second indirect effect}

Precipitation efficiency in clouds can be identified by means of changes in LWP with respect to CER. Larger the LWP lesser will be the precipitation efficiency (Reid and Hobbs, 1998; Schwartz et al., 2002). Several studies have shown that both LWP and CER change with varying aerosol concentrations (Minnis et al., 1992; Han et al., 1994). Figure 4 depicts the scatter plot between LWP and CER for both nonmonsoon and monsoon months. It is seen that during nonmonsoon months, a decrease in CER results in an increase 
in LWP. The scatter plot shows that they are anti-correlated with a correlation coefficient of -0.68 .

This result is in accordance with the observations made by Rosenfeld (1999) and Ferek et al. (2000) in which they show that smaller CER lead to an increase in LWP suppressing drizzle formation in smoke plumes and ship tracks. The suppression of drizzle enhances cooling below the cloud base because smaller droplets evaporate more quickly. This cooling acts along with the radiative heating of the cloud base to suppress turbulent mixing, de-coupling the cloud from the rest of the boundary layer restricting the supply of water vapour. This reduction in water vapour from the surface leads to decrease in LWP and thinning of the cloud layer. During nonmonsoon months the clouds present over the region will be optically thinner which is evident from the lower LWP values. These values during non-monsoon months are found to be less than $80 \mathrm{~g} \mathrm{~m}^{-2}$. For a cloud to precipitate it is required to attain larger value of LWP so as to maintain its precipitation efficiency. When the CER decreases, the drag on the updrafts produced by raindrops gets reduced, allowing a greater number of smaller droplets to reach higher altitudes, causing additional latent heat when they freeze. Therefore the stability of the atmosphere at the lower levels gets increased further inhibiting the possibility of precipitation. Such a condition is more pronounced in a polluted environment as that in IGP. The water droplets that are unable to precipitate remain in the atmosphere, and accounts for the higher water content in clouds.

An increase in water loading in the clouds suggests a reduction in the precipitation efficiency. As a result, when the CER becomes very small (in the range of 10 to $11 \mathrm{mi}-$ crons) there is an appreciable rise in LWP to as high as 80 to $90 \mathrm{~g} \mathrm{~m}^{-2}$. When the CER increases to 12 microns and above there is a depletion of LWP to below $60 \mathrm{~g} \mathrm{~m}^{-2}$. In short, it can be ascertained that when CER increases the LWP in the clouds get depleted. In a polluted environment this reduction of LWP is attributed to the entrainment of dry air into clouds resulting in an evaporation of cloud droplets (Ackerman et al., 2004).

In the monsoon season a high positive correlation of 0.83 exists between CER and LWP. It can be reasoned that the positive correlation is seen between LWP and CER during the monsoon season is due to the dominant presence of marine air-mass. In such a state, the atmosphere will be predominantly composed of coarse mode aerosol particles. Therefore, as suggested by Rosenfeld et al. (2002), these coarse mode hygroscopic $\mathrm{CCN}$ override the precipitationsuppression effect of the large number of finite aerosols formed from anthropogenic sources. At high concentrations, these large aerosol particles undergo collision and coagulation and may grow to precipitation size by collecting small cloud droplets. Coagulation process is more enhanced when there is fast relative particle motion such as that occurring in shearing or turbulent flows. These types of flows are more frequent in the monsoon season so that it induces increased
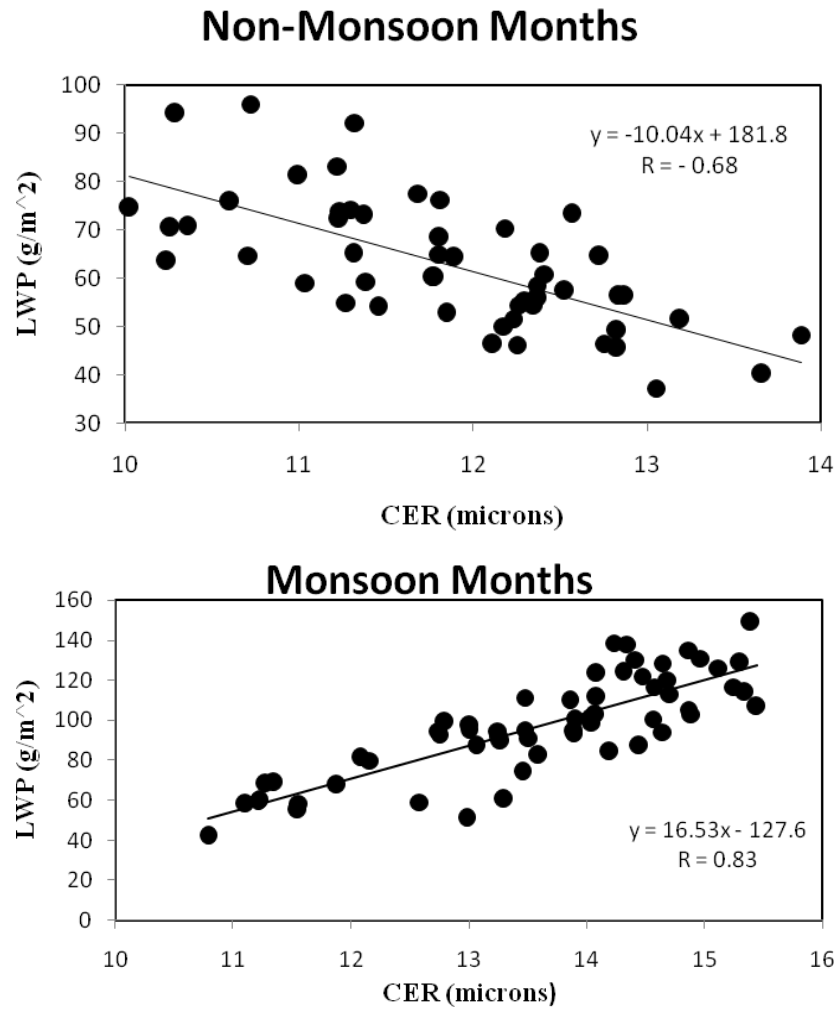

Fig. 4. Scatter diagram between LWP and CER for (a) nonmonsoon months and (b) monsoon months.

coagulation rates between particles. Therefore, the coagulation of particles at higher concentrations rapidly reduces the number density of finer mode of aerosols while increasing the droplet size, which explains the higher LWP during the monsoon season.

Availability of enormous amount of humidity is another important factor that has to be taken into account during the monsoon season. In this season, the relative humidity (RH) is very high; as a result it gives an opportunity for the increase in water vapour condenses upon aerosol particles. Eventually, these particles begin to grow with increasing RH. This growth in particle diameter intensifies the thickness of cloud which is explained by increasing values during the monsoon season. The water holding capacity of the cloud droplet intensifies with the buildup of the LWP and this explains the close association between LWP and CER.

Present study confirms that the aerosol first and second indirect effects are occurring over the region and as pointed out by Ramanathan et al. (2001), the enhanced loading of fine mode aerosols should lead to a reduction in precipitation. The associated modifications in thermal stability should influence the atmospheric circulation thereby affecting the monsoon progression and onset over the region. 


\section{Conclusion}

Taking into consideration on the limitations attributed to the MODIS data sets, we summarize the results obtained from the present study as follows. During non-monsoon months there is indeed a decrease in CER with increase in aerosol concentration which is in accordance with well known first indirect effect or "Twomey effect". Fine mode aerosols which are present in large quantities during these months are responsible for the inverse relationship existing between these two parameters. This inverse relationship is more prominent in the non-monsoon months of the years 2004, 2009 and 2010 for which El-Niño conditions occurred. The pre-monsoon seasons of 2004, 2009 shows an abnormal rise in fine mode AOD to 0.3. A significant reduction in CER is observed and following monsoon season was in the region. Quantitative analysis establishes the negative correlation between CER and AOD during the non-monsoon months at a correlation coefficient of 0.62 . It is seen that in the month of May, when the CER diminished below 12 microns, there was a delay in advancement and onset of monsoon over North India even after a normal or early onset over southern peninsula. In the years 2000 and 2004 when CER was above 12 microns, there was a rapid advancement of monsoon towards the region. Highest AOD of the last decade was recorded in the year 2010 resulting in a reduction of CER to its least value in the month of January. Subsequently, there has been a deficiency of $24 \%$ in June rainfall alone and monsoon was a failure in the entire season over the region while rest of the country received above normal rainfall. The present analysis further reveals that the AOD value in January may be a precursor to the performance of the following monsoon season. Moreover, LWP and CER exhibit an inverse correlation of 0.68 during non-monsoon months, while high positive correlation of 0.83 existed during monsoon months. The analysis manifests that a change in cloud particle size affects the precipitation efficiency in the clouds negatively during the non-monsoon months. These results signify that "second indirect effect" indeed occurs and a decrease in CER affects the onset of precipitation in clouds. Therefore, from these results, it can be postulated that the combination of both the first and second indirect effects act to influence the monsoon onset and its progression towards the North Indian region.

Acknowledgements. The first author (BA) would like to thank the Council for Scientific and Industrial Research (CSIR), New Delhi for providing Research Fellowship. MODIS data used in this study is produced with the Giovanni online data system, developed and maintained by the NASA Goddard Earth Sciences (GES) Data and Information Services Center (DISC).

Topical Editor P. M. Ruti thanks two anonymous referees for their help in evaluating this paper.

\section{References}

Ackerman, A. S., Toon, O. B., Stevens, D. E., Heymsfeld, A. J., Ramanathan, V., and Welton, E. J.: Reduction of tropical cloudiness by soot, Science, 288, 1042-1047, 2000.

Ackerman, A. S., Kirkpatrick, M. P., Stevens, D. E., and Toon, O. B.: The impact of humidity above stratiform clouds on indirect aerosol climate forcing, Nature, 432, 1014-1017, 2004.

Albrecht, B. A.: Aerosols, cloud microphysics, and fractional cloudiness, Science, 245, 1227-1230, 1989.

Aloysius, M., Mohan, M., Parameswaran, K., George, S. K., and Nair, P. R.: Aerosol transport over the Gangetic basin during ISRO-GBP land campaign-II, Ann. Geophys., 26, 431-440, doi:10.5194/angeo-26-431-2008, 2008.

Bellouin, N., Jones, A., Haywood, J., and Christopher, S. A.: Updated estimate of aerosol direct radiative forcing from satellite observations and comparison against the Hadley Centre climate model, J. Geophys. Res., 113, D10205, doi:10.1029/2007JD009385, 2008.

Bhawar, R. L. and Devara, P. C. S.: Study of successive contrasting monsoons (2001-2002) in terms of aerosol variability over a tropical station Pune, India, Atmos. Chem. Phys., 10, 29-37, doi:10.5194/acp-10-29-2010, 2010.

Bollasina, M., Nigam, S., and Lau, K. M.: Absorbing aerosols and summer monsoon evolution over South Asia: An Observational Portrayal, J. Climate, 21, 3221-3239, doi:10.1175/2007JCLI2094.1, 2008.

Chung, C. E. and Ramanathan, V.: Aerosol loading over the Indian Ocean and its possible impact on regional climate, Ind. J. Mar. Sci., 33, 40-55, 2004.

Dey, S., Tripathi, S. N., Singh, R. P., and Holben, B. N.: Influence of dust storms on the aerosol optical properties over the Indo-Gangetic plains, J. Geophys. Res., 109, D20211, doi:10.1029/2004JD004924, 2004.

Ferek, R. J., Garrett, T., Hobbs, P., Strader, S., Johnson, D., Taylor, J. P., Nielsen, K., Ackerman, A. S., Kogan, Y., Liu, Q., Albrecht, B. A., and Babb, D.: Drizzle suppression in ship tracks, J. Atmos. Sci., 26, 2707-2728, 2000.

Gautam, R., Hsu, N. C., Lau, K.-M., and Kafatos, M.: Aerosol and rainfall variability over the Indian monsoon region: distributions, trends and coupling, Ann. Geophys., 27, 3691-3703, doi:10.5194/angeo-27-3691-2009, 2009.

Habib, G., Venkataraman, C., Chiapello, I., Ramachandran, S., Boucher, O., and Reddy, M. S.: Seasonal and interannual variability in absorbing aerosols over India derived from TOMS: Relationship to regional meteorology and emissions, Atmos. Environ., 40, 1909-1921, 2006.

Han, Q., Rossow, W. B., and Lacis, A. A.: Near-global survey of effective droplet radii in liquid water clouds using ISCCP data, J. Climate, 7, 465-497, 1994.

Jethva, H., Satheesh, S. K., and Srinivasan, J.: Seasonal variability of aerosols over the Indo-Gangetic basin, J. Geophys. Res., 110, D21204, doi:10.1029/2005JD005938, 2005.

Jethva, H., Satheesh, S. K., and Srinivasan, J.: Assessment of second generation MODIS aerosol retrieval (Collection 005) at Kanpur, India, Geophys. Res. Lett., 34, L19802, doi:10.1029/2007GL029647, 2007.

Jones, T. A. and Christopher, S. A.: Statistical variability of top of atmosphere cloud-free shortwave aerosol radiative effect, Atmos. Chem. Phys., 7, 2937-2948, doi:10.5194/acp-7-2937-2007, 
2007.

Kaufman, Y. J., Tanre, D., Remer, L., Vermote, E., Chu, A., and Holben, B. N.: Operational remote sensing of tropospheric aerosol over land from EOS Moderate Resolution Imaging Spectroradiometer, J. Geophys.Res., 102, 17051-17067, 1997.

Kaufman, Y. J., Boucher, O., Tanré, D., Chin, M., Remer, L. A., and Takemura, T.: Aerosol anthropogenic component estimated from satellite data, Geophys. Res. Lett., 32, L17804, doi:10.1029/2005GL023125, 2005.

Khain, A. P., Rosenfeld, D., and Pokrovsky, A.: Simulating convective clouds with sustained super cooled liquid water down to $-37.5^{\circ} \mathrm{C}$ using a spectral microphysics model, Geophys. Res. Lett., 28, 3887-3890, 2001.

Koren, I., Kaufman, Y. J., Rosenfeld, D., Remer, L. A., and Rudich, Y.: Aerosol invigoration and restructuring of Atlantic convective clouds, Geophys. Res. Lett., 32, L14828, doi:10.1029/2005GL023187, 2005.

Lau, K. M. and Kim, K. M.: Observational relationships between aerosol and Asian monsoon rainfall, and circulation, Geophys. Res. Lett., 33, L21810, doi:10.1029/2006GL027546, 2006.

Lau, K. M., Kim, M. K., and Kim, K. M.: Asian monsoon anomalies induced by aerosol direct effects, Clim. Dynam., 26, 855864, doi:10.1007/s00382-006-0114-z, 2006.

Léon, J. F. and Legrand, M.: Mineral dust sources in the surroundings of the north Indian Ocean, Geophys. Res. Lett., 30, 13091313,2003

Levy, R. C., Remer, L., Mattoo, S., Vermote, E., and Kaufman, Y. J.: Second-generation algorithm for retrieving aerosol properties over land from MODIS spectral reflectance, J. Geophys. Res., 112, 13211, doi:10.1029/2006JD007811, 2007.

Liao, H. and Seinfeld, J. H.: Effect of clouds on direct aerosol radiative forcing of climate, J. Geophys. Res., 103, 3781-3788, 1998.

Martins, J. A., Silva Dias, M. A. F., and Gonçalves, F. L. T.: Impact of biomass burning aerosols on precipitation in the Amazon: A modeling case study, J. Geophys. Res., 114, D02207, doi:10.1029/2007JD009587, 2009.

Menon, S., Hansen, J., Nazarenko, L., and Luo, Y.: Climate effects of black carbon aerosols in China and India, Science, 297, 2250 2253, 2002.

Miller, R. L., Tegen, I., and Perlwitz, J.: Surface radiative forcing by soil dust aerosols and the hydrologic cycle, J. Geophys. Res., 109, D04203, doi:10.1029/2003JD004085, 2004.

Minnis, P., Heck, P. W., Young, D. F., Fairall, C. W., and Snider, J. B.: Stratocumulus cloud properties derived from simultaneous satellite and island-based instrumentation during FIRE, J. Appl. Meteor., 31, 317-339, 1992.

Nair, V. S., Krishnamoorthy, K., Denny, P. A., Kunhikrishnan, P. K., George, S., Nair, P. R., Suresh Babu, S., Abish, B., Satheesh, S. K., Sachchidanand Tripathi, Niranjan, K., Madhavan, B. L., Srikant, V., Dutt, C. B. S., Badarinath, K. V. S., and Ramakrishna Reddy, R.: Wintertime aerosol characteristics over the Indo-Gangetic Plain (IGP): Impacts of local boundary layer processes and long-range transport, J. Geophys. Res., 112, D13205, doi:10.1029/2006JD008099, 2007.

O’Neill, N. T., Eck, T. F., Smirnov, A., Holben, B. N., and Thulasiraman, S.: Spectral discrimination of coarse and fine mode optical depth, J. Geophys. Res., 108, 4559-4573, doi:10.1029/2002JD002975, 2003.

Pai, D. S. and Rajeevan, M.: Summer monsoon onset over Kerala:
New definition and prediction, J. Earth Syst. Sci., 118, 123-135, 2009.

Panicker, A. S., Pandithurai, G., and Dipu, S.: Aerosol indirect effect during successive contrasting monsoon seasons over Indian subcontinent using MODIS data, Atmos. Environ., 44, 19371943, 2010.

Patra, P. K., Behera, S. K., Herman, J. R., Maksyutov, S., Akimoto, H., and Yamagata, Y.: The Indian summer monsoon rainfall: interplay of coupled dynamics, radiation and cloud microphysics, Atmos. Chem. Phys., 5, 2181-2188, doi:10.5194/acp-5-21812005, 2005.

Penner, J. E., Dong, X., and Chen, Y.: Observational evidence of a change in radiative forcing due to the indirect aerosol effect, Nature, 427, 231-234, 2004.

Ram, K. and Sarin, M. M.: Spatio-temporal variability in atmospheric abundances of EC, OC and WSOC over Northern India, J. Aerosol Sci., 41, 88-98, 2010.

Ramanathan, V. and Ramana, M. V.: Persistent, widespread, and strongly absorbing haze over the Himalayan foothills and the Indo-Gangetic Plains, Pure Appl. Geophys., 162, 1609-1626, 2005.

Ramanathan, V., Crutzen, P. J., Lelieveld, J., Mitra, A. P., Althausen, D., Anderson, J., Andreae, M. O., Cantrell, W., Cass, G. R., Chung, C. E., Clarke, A. D., Coakley, J. A., Collins, W. D., Conant, W. C., Dulac, F., Heintzenberg, J., Heymsfield, A. J., Holben, B., Howell, S., Hudson, J., Jayaraman, A., Kiehl, J. T., Krishnamurti, T. N., Lubin, D., Macfarquhar, G., Novakov, T., Ogren, J. A., Podgorny, I. A., Prather, K., Priestley, K., Prospero, J. M., Quinn, P. K., Rajeev, K., Rasch, P., Rupert, S., Sadourny, R., Satheesh, S. K., Shaw, G. E., Sheridan, P., and Valero, F. P. J.: Indian Ocean Experiment: An integrated analysis of the climate forcing and effects of the great Indo-Asian haze, J. Geophys. Res., 106, 28378-28398, 2001.

Ravi Kiran, V., Rajeevan, M., Vijaya Bhaskara Rao, S., and Prabhakara Rao, N.: Analysis of variations of cloud and aerosol properties associated with active and break spells of Indian summer monsoon using MODIS data, Geophys. Res. Lett., 36, L09706, doi:10.1029/2008GL037135, 2009.

Reid, J. S. and Hobbs, P. V.: Physical and optical properties of young smoke from individual biomass fires in Brazil, J. Geophys. Res., 103, 32013-32030, 1998.

Remer, L. A., Kleidman, R. G., Levy, R. C., Kaufman, Y. J., Tanré, D., Mattoo, S., Martins, J. V., Ichoku, C., Koren, I., Yu, H., and Holben, B. N.: Global aerosol climatology from the MODIS satellite sensors, J. Geophys. Res., 113, D14S07, doi:10.1029/2007JD009661, 2008

Rosenfeld, D.: TRMM observed first direct evidence of smoke from forest fires inhibiting rainfall, Geophys. Res. Lett., 26, 3105 3108, 1999.

Rosenfeld, D. and Woodley, W. L.: Deep convective clouds with sustained supercooled liquid water down to $-37.5^{\circ} \mathrm{C}$, Nature, 405, 440-442, 2000.

Rosenfeld, D., Lahav, R., Khain, A., and Pinsky, M.: The role of sea spray in cleansing air pollution over the ocean via cloud processes, Science, 297, 1667-1670, 2002.

Rosenfeld, D., Kaufman, Y. J., and Koren, I.: Switching cloud cover and dynamical regimes from open to closed Benard cells in response to the suppression of precipitation by aerosols, Atmos. Chem. Phys., 6, 2503-2511, doi:10.5194/acp-6-2503-2006, 
2006.

Schwartz, S. E., Harshvardhan, and Benkovitz, C. M.: Influence of anthropogenic aerosol on cloud optical depth and albedo shown by satellite measurements and chemical transport modeling, Proc. Natl. Acad. Sci. USA, 99, 1784-1789, 2002.

Tare, V., Tripathi, S. N., Chinnam, N., Srivastava, A. K., Dey, S., Manar, M., Kanawade, V. P., Agarwal, A., Kishore, S., Lal, R. B., and Sharma, M.: Measurements of atmospheric parameters during ISRO-GBP land campaign II at a typical location in Ganga basin: part II-chemical properties, J. Geophys. Res., 111, D23210, doi:10.1029/2006JD007279, 2006.

Tripathi, S. N., Pattnaik, A., and Dey, S.: Aerosol indirect effect over Indo-Gangetic plain, Atmos. Environ., 41, 7037-7047, 2007.
Twomey, S.: The influence of pollution on the shortwave albedo of clouds, J. Atmos. Sci., 34, 1149-1152, 1977.

Wang, C., Kim, D., Ekman, A. M. L., Barth, M. C., and Rasch, P. J.: Impact of anthropogenic aerosols on Indian summer monsoon, Geophys. Res. Lett., 36, L21704, doi:10.1029/2009GL040114, 2009.

Yu, H., Chin, M., Remer, L. A., Kleidman, R., Bellouin, N., Blan, H., and Diehl, T.: Variability of marine aerosol fine mode fraction estimates of anthropogenic aerosol component over cloud-free oceans from the Moderate Resolution Imaging Spectroradiometer (MODIS), J. Geopys. Res., 114, D10206, doi:10.1029/2008JD010648, 2009. 